\title{
Kinetic and Thermodynamic Requirements to Extend Solvent Compatibility in Thermal-Assisted Extraction of Inert Platinum Group Metals
}

\author{
Zhiwei Zheng, ${ }^{1}$ Tsuyoshi Arai, ${ }^{2}$ Koichiro Takao ${ }^{1 *}$ \\ ${ }^{1}$ Laboratory for Advanced Nuclear Energy, Institute of Innovative Research, Tokyo Institute of Technology, 2-12- \\ 1 N1-32, O-okayama, Meguro-ku, 152-8550 Tokyo, Japan. \\ ${ }^{2}$ Graduate School of Engineering, Shibaura Institute of Technology, 3-7-5, Toyosu, Koto-ku, 135-8548 Tokyo, Japan.
}

\section{List of Contents}

\section{Experimental Procedure}

Figure S1. ${ }^{19} \mathrm{~F}$ NMR spectra of $\mathrm{Tf}_{2} \mathrm{~N}^{-}(\mathrm{a}), \mathrm{TfO}^{-}(\mathrm{b}), \mathrm{BF}_{4}^{-}$(c) and $\mathrm{PF}_{6}^{-}$(d) in DMSOS2 $\mathrm{d}_{6}$. Concentration of each anion in the organic phase was determined after partitioning 1-octanol / 0.5 $\mathrm{M} \mathrm{HNO}_{3}(\mathrm{aq})$. $\mathrm{TBAPF}_{6}$ was employed as a standard for $\mathrm{Tf}_{2} \mathrm{~N}^{-}$, $\mathrm{TfO}^{-}$, and $\mathrm{BF}_{4}^{-}$, while that for $\mathrm{PF}_{6}^{-}$was $\mathrm{LiTf}_{2} \mathrm{~N}$.

Figure S2. Effect of total concentration of $\mathrm{Tf}_{2} \mathrm{~N}^{-}\left(\left[\mathrm{Tf}_{2} \mathrm{~N}^{-}\right]_{\text {aq }}\right)$ to $\mathrm{Ru}(\mathrm{III})(5 \mathrm{mM})$ extraction from $0.5 \mathrm{M} \mathrm{HNO}_{3}$ (aq) to 1-octanol containing $30 \mathrm{mM}$ TBPDA at $356 \mathrm{~K}$ in terms of $D$.

Figure S3. Effect of concentration of $\mathrm{NO}_{3}^{-}$to $\mathrm{Ru}(\mathrm{III})(5 \mathrm{mM})$ extraction from $(\mathrm{H}, \mathrm{Na}) \mathrm{NO}_{3}(\mathrm{aq})$ containing $0.5 \mathrm{M} \mathrm{H}^{+}$to 1 -octanol containing $60 \mathrm{mM}$ TBPDA at $356 \mathrm{~K}$ in terms of $D$.

Figure S4. Effect of concentration of TBPDA to $\mathrm{Ru}(\mathrm{III})(5 \mathrm{mM})$ extraction from 0.5 $\mathrm{M} \mathrm{HNO}_{3}$ (aq) containing $50 \mathrm{mM} \mathrm{LTf}{ }_{2} \mathrm{~N}$ (red) and without $\mathrm{LTf}_{2} \mathrm{~N}$ (black) to 1 -octanol at $356 \mathrm{~K}$ in terms of $D$.

Figure S5. Extraction efficiency $(E \%)$ of $\mathrm{Ru}(\mathrm{III})$ as a function of elapsed time in 0.5 $\mathrm{M} \mathrm{HNO}_{3}(\mathrm{aq}) / 1$-octanol system. Condition: $[\mathrm{Ru}(\mathrm{III})]=5 \mathrm{mM}$, [TBPDA] $=30 \mathrm{mM}$, [anion] $=500 \mathrm{mM}, T=356 \mathrm{~K}$.

Table S1. Correlation between Partition Coefficient $(\log P)$ and $\mathrm{Ru}(\mathrm{III})(5 \mathrm{mM})$ Extraction Behavior in $0.5 \mathrm{M} \mathrm{HNO}_{3}(\mathrm{aq}) / 1$-Octanol System

Figure S6. Effect of total concentration of $\mathrm{Tf}_{2} \mathrm{~N}^{-}\left(\left[\mathrm{Tf}_{2} \mathrm{~N}^{-}\right]_{\text {tot }}\right)$ to $\mathrm{Rh}(\mathrm{III})(5 \mathrm{mM})$ extraction from $0.5 \mathrm{M} \mathrm{HNO}_{3}(\mathrm{aq})$ to 1 -octanol containing $30 \mathrm{mM}$ TBPDA at $356 \mathrm{~K}$ in terms of $D$. 


\section{Experimental Procedure.}

All of the chemicals were of reagent grade and used without further purification. 2,6pyridinedicarbonyl dichloride (1.96 g, Wako Chemical Ltd.) and triethylamine $(2.68 \mathrm{~mL}=1.95$ g, Kanto Chemical Co., Inc.) were dissolved to THF (40 mL, Kanto Chemical Co., Inc.) in 100 $\mathrm{mL}$ round-bottom flask. The mixture was cooled on ice bath. After THF $(5 \mathrm{ml})$ which containing di-n-butylamine $(3.25 \mathrm{~mL}=2.49 \mathrm{~g}$, Tokyo Chemical Industry Co., LTD.) was slowly added by a dropping funnel, additional THF $(10 \mathrm{ml})$ was further loaded. The mixture was stirred for $1 \mathrm{~h}$ on the ice bath, and stirred at RT for overnight. White precipitate was removed. The filtrate was concentrated by rotary evaporator. The residue in the flask was dissolved in dichloromethane (30 mL, FUJIFILM Wako Pure Chemical Corporation), and mixed with $2 \mathrm{M} \mathrm{HCl}(\mathrm{aq})(6 \mathrm{~mL})$. The organic layer was transferred to another flask, mixed with small portion of $\mathrm{K}_{2} \mathrm{CO}_{3}$ and $\mathrm{MgSO}_{4}$, and rested for $15 \mathrm{~min}$. Then solid materials were removed by filtration. Any volatile materials in the filtrate was removed by the rotary evaporator to give yellow oil of TBPDA ( $2.17 \mathrm{~g}, 58 \%$ yield). The obtained compound was characterized by ${ }^{1} \mathrm{H}$ and ${ }^{13} \mathrm{C}$ NMR spectroscopy (JEOL JNM ECX400). ${ }^{1} \mathrm{H}$ NMR ( $\mathrm{CDCl}_{3}, \delta / \mathrm{ppm}$ vs. TMS) 0.79 (t, 6H, $\left.\mathrm{NCH}_{2} \mathrm{CH}_{2} \mathrm{CH}_{2} \mathrm{CH}_{3}\right), 0.98$ (t, 6H, $\mathrm{NCH}_{2} \mathrm{CH}_{2} \mathrm{CH}_{2} \mathrm{CH}_{3}$ ), 1.14 (sextet, $4 \mathrm{H}, \mathrm{NCH}_{2} \mathrm{CH}_{2} \mathrm{CH}_{2} \mathrm{CH}_{3}$ ), 1.40 (sextet, $4 \mathrm{H}, \mathrm{NCH}_{2} \mathrm{CH}_{2} \mathrm{CH}_{2} \mathrm{CH}_{3}$ ), $1.54\left(\mathrm{~m}, 4 \mathrm{H}, \quad \mathrm{NCH}_{2} \mathrm{CH}_{2} \mathrm{CH}_{2} \mathrm{CH}_{3}\right), 1.66\left(\mathrm{~m}, 4 \mathrm{H}, \mathrm{NCH}_{2} \mathrm{CH}_{2} \mathrm{CH}_{2} \mathrm{CH}_{3}\right), 3.30$ (dd, 4H, $\left.\mathrm{NCH}_{2} \mathrm{CH}_{2} \mathrm{CH}_{2} \mathrm{CH}_{3}\right), 3.49$ (dd, $\left.4 \mathrm{H}, \mathrm{NCH}_{2} \mathrm{CH}_{2} \mathrm{CH}_{2} \mathrm{CH}_{3}\right), 7.61(\mathrm{~d}, 2 \mathrm{H}, 3,5-\mathrm{H}), 7.86(\mathrm{t}$ ?, 1H, 4-H). ${ }^{13} \mathrm{C} \mathrm{NMR}\left(\mathrm{CDCl}_{3}\right.$, $\delta / \mathrm{ppm}$ vs. TMS $)$ 13.83, 14.01, 19.88, 20.41, 29.70, 31.10, 45.73, 48.71, 123.90, $137.91,153.64,168.30$.

The pre-equilibrated $\mathrm{HNO}_{3}(\mathrm{aq})$ which containing a metal ion (M) like $5 \mathrm{mM} \mathrm{Ru}(\mathrm{III})$ or $5 \mathrm{mM}$ $\mathrm{Rh}$ (III) was loaded into a screw-capped vial with a pre-equibrated organic solvent (1-octanol or [choline][Tf $\left.{ }_{2} \mathrm{~N}\right]$ ) which containing $30 \mathrm{mM}$ TBPDA. The volume ratio between aqueous and organic phases were always kept in 1:1. The mixture was stirred at $800 \mathrm{rpm}$ and constant temperature in aluminum block bath on a hot stirrer. For analysis, small amount of mixture was cooled to RT then centrifuged. The M concentration in aqueous layer was determined by ICPAES (Thermo Scientific iCAP7200 Duo). The extraction efficiency $(E \%)$ and the distribution ratio $(D)$ were calculated as follows.

$$
\begin{aligned}
E \% & =100 \times\left([\mathrm{M}]_{\text {ini }}-[\mathrm{M}]_{\mathrm{aq}}\right) /[\mathrm{M}]_{\text {ini }} \\
D & =\left([\mathrm{M}]_{\text {ini }}-[\mathrm{M}]_{\mathrm{aq}}\right) /[\mathrm{M}]_{\mathrm{aq}}
\end{aligned}
$$

where $[M]_{\text {ini }}$ and $[M]_{\text {aq }}$ denote the metal concentrations in the aqueous phase at the initial state and after the extraction, respectively.

Lithium salts of $\mathrm{Tf}_{2} \mathrm{~N}^{-}, \mathrm{TfO}^{-}, \mathrm{BF}_{4}^{-}, \mathrm{PF}_{6}^{-}$, and $\mathrm{ClO}_{4}^{-}(500 \mathrm{mM})$ were dissolved in the preequilibrated $0.5 \mathrm{M} \mathrm{HNO}_{3}$ (aq). The partition behavior of these anions was examined by contacting with the pre-equilibrated 1-octanol at 1:1 volume ratio. After $1 \mathrm{~h}$ mixing for equilibration, the organic layer $(70 \mu \mathrm{L})$ was mixed with a DMSO- $\mathrm{d}_{6}$ solution $(630 \mu \mathrm{L})$ dissolving a standard material. Concentrations of $\mathrm{Tf}_{2} \mathrm{~N}^{-}, \mathrm{TfO}^{-}$, and $\mathrm{BF}_{4}^{-}$in organic layer were determined by ${ }^{19} \mathrm{~F} \mathrm{NMR}$ peak integrals compared with that of tetrabutylammonium hexafluorophosphate $\left(\mathrm{TBAPF}_{6}\right)$ as a reference. $\operatorname{LiTf}_{2} \mathrm{~N}$ was employed as a reference for $\mathrm{PF}_{6}{ }^{-}$. The $\log P$ of $\mathrm{ClO}_{4}{ }^{-}$was indirectly determined from distribution of $\mathrm{Li}^{+}$evaluated by ICP-AES. 

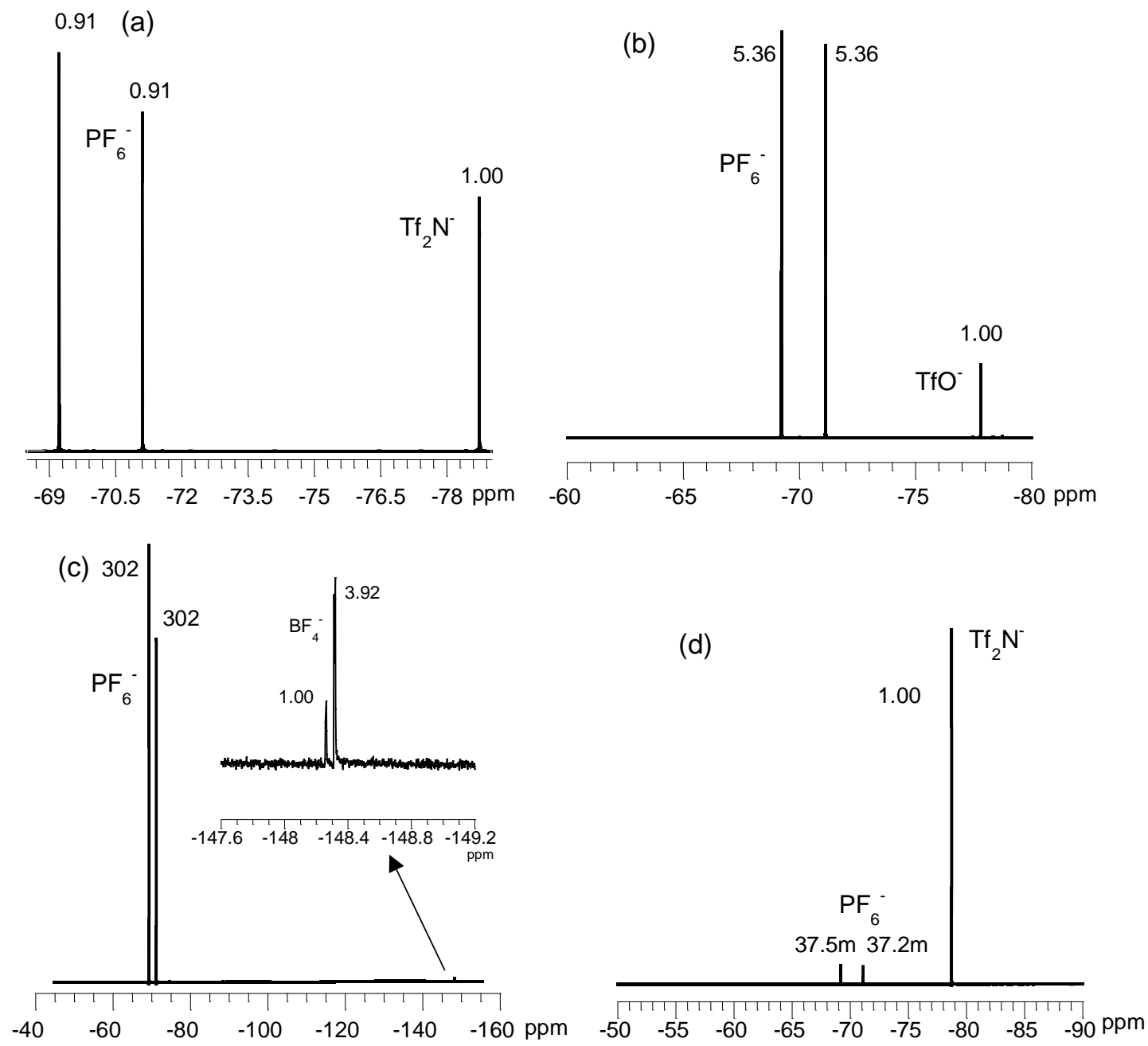

Figure S1. ${ }^{19} \mathrm{~F}$ NMR spectra of $\mathrm{Tf}_{2} \mathrm{~N}^{-}$(a), $\mathrm{TfO}^{-}(\mathrm{b}), \mathrm{BF}_{4}^{-}$(c) and $\mathrm{PF}_{6}^{-}$(d) in DMSO-d 6 .

Concentration of each anion in the organic phase was determined after partitioning 1-octanol / $0.5 \mathrm{M} \mathrm{HNO}_{3}(\mathrm{aq})$. $\mathrm{TBAPF}_{6}$ was employed as a standard for $\mathrm{Tf}_{2} \mathrm{~N}^{-}, \mathrm{TfO}^{-}$, and $\mathrm{BF}_{4}^{-}$, while that for $\mathrm{PF}_{6}{ }^{-}$was $\mathrm{LiTf}_{2} \mathrm{~N}$. 


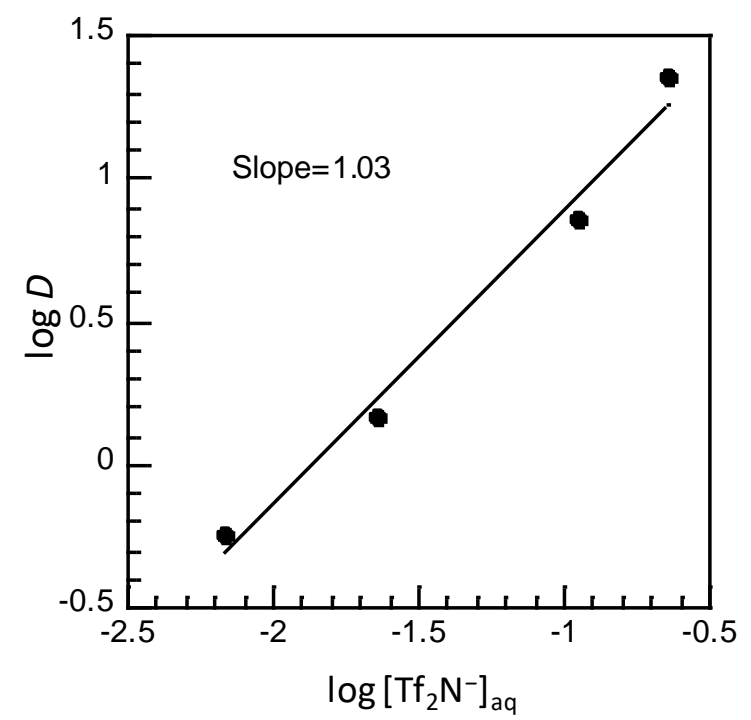

Figure S2. Effect of total concentration of $\mathrm{Tf}_{2} \mathrm{~N}^{-}\left(\left[\mathrm{Tf}_{2} \mathrm{~N}^{-}\right]_{\text {aq }}\right)$ to $\mathrm{Ru}(\mathrm{III})(5 \mathrm{mM})$ extraction from $0.5 \mathrm{M} \mathrm{HNO}_{3}(\mathrm{aq})$ to 1 -octanol containing $30 \mathrm{mM}$ TBPDA at $356 \mathrm{~K}$ in terms of $D$.

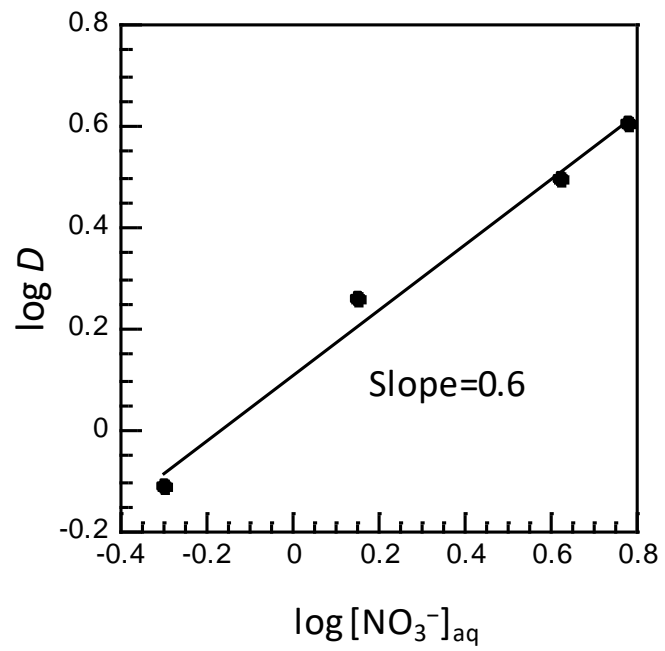

Figure S3. Effect of concentration of $\mathrm{NO}_{3}{ }^{-}$to $\mathrm{Ru}(\mathrm{III})(5 \mathrm{mM})$ extraction from $(\mathrm{H}, \mathrm{Na}) \mathrm{NO}_{3}(\mathrm{aq})$ containing $0.5 \mathrm{M} \mathrm{H}^{+}$to 1 -octanol containing $60 \mathrm{mM}$ TBPDA at $356 \mathrm{~K}$ in terms of $D$. 


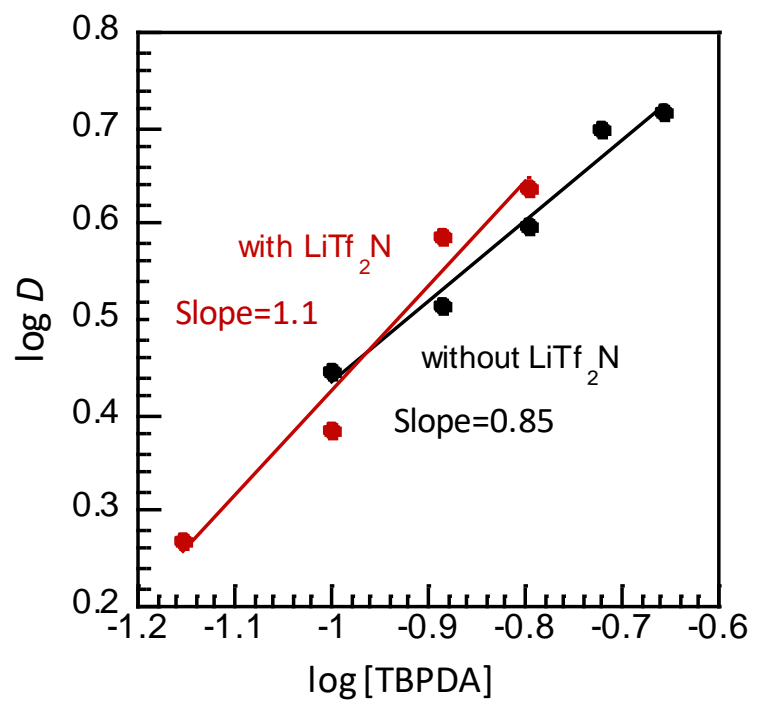

Figure S4. Effect of concentration of TBPDA to $\mathrm{Ru}(\mathrm{III})(5 \mathrm{mM})$ extraction from $0.5 \mathrm{M} \mathrm{HNO}_{3}(\mathrm{aq})$ containing $50 \mathrm{mM} \mathrm{LTf}_{2} \mathrm{~N}$ (red) and without $\mathrm{LTf}_{2} \mathrm{~N}$ (black) to 1 -octanol at $356 \mathrm{~K}$ in terms of $D$.

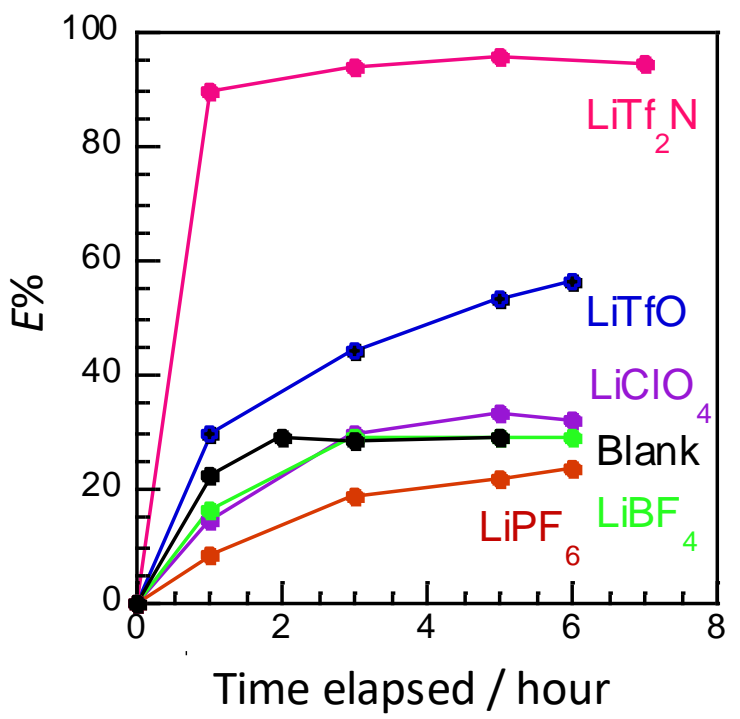

Figure S5. Extraction efficiency $(E \%)$ of $\mathrm{Ru}(\mathrm{III})$ as a function of elapsed time in $0.5 \mathrm{M}$ $\mathrm{HNO}_{3}(\mathrm{aq}) / 1$-octanol system. Condition: $[\mathrm{Ru}(\mathrm{III})]=5 \mathrm{mM}$, [TBPDA $]=30 \mathrm{mM}$, [anion] $=500$ $\mathrm{mM}, T=356 \mathrm{~K}$. 
Table S1. Correlation between Partition Coefficient ( $\log P$ ) and $\mathrm{Ru}(\mathrm{III})(5 \mathrm{mM})$ Extraction Behavior in $0.5 \mathrm{M} \mathrm{HNO}_{3}(\mathrm{aq}) / 1-$ Octanol System

\begin{tabular}{cccc}
\hline anion & $\log P$ & $E \%$ & $\log D$ \\
\hline $\mathrm{Tf}_{2} \mathrm{~N}^{-}$ & 0.09 & 94.8 & 1.36 \\
$\mathrm{TfO}^{-}$ & -0.64 & 56.4 & 0.11 \\
$\mathrm{PF}_{6}{ }^{-}$ & -1.09 & 23.6 & -0.51 \\
$\mathrm{ClO}_{4}^{-}$ & -1.40 & 32.0 & -0.33 \\
$\mathrm{BF}_{4}^{-}$ & -1.91 & 29.3 & -0.38 \\
\hline
\end{tabular}

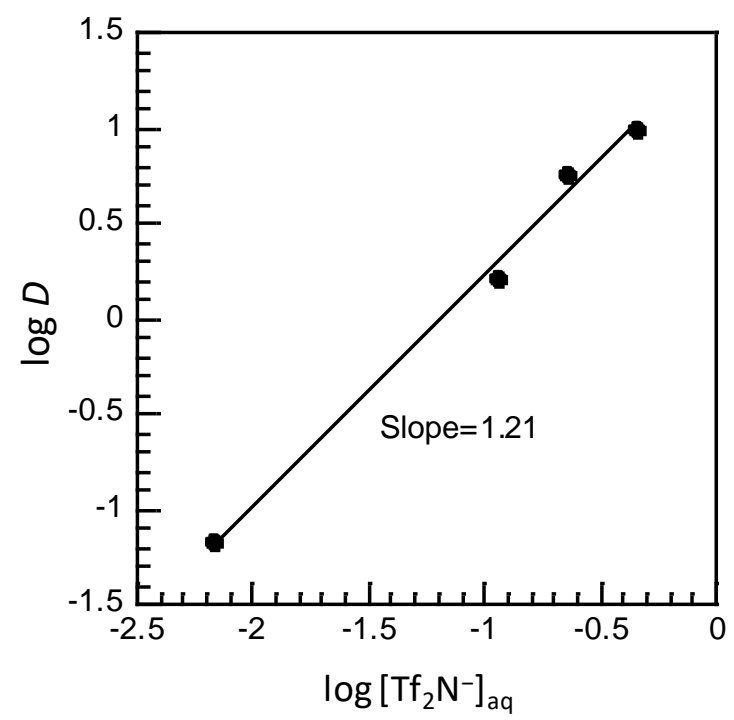

Figure S6. Effect of total concentration of $\mathrm{Tf}_{2} \mathrm{~N}^{-}\left(\left[\mathrm{Tf}_{2} \mathrm{~N}^{-}\right]_{\text {tot }}\right)$ to $\mathrm{Rh}(\mathrm{III})(5 \mathrm{mM})$ extraction from $0.5 \mathrm{M} \mathrm{HNO}_{3}(\mathrm{aq})$ to 1 -octanol containing $30 \mathrm{mM}$ TBPDA at $356 \mathrm{~K}$ in terms of $D$. 